\title{
Risk of human papillomavirus-related cancers among kidney transplant recipients and patients receiving chronic dialysis - an observational cohort study
}

Lars Skov Dalgaard ${ }^{1 *}$, Ulrik Fassel ${ }^{2}$, Lars Jørgen Østergaard ${ }^{1}$, Bente Jespersen ${ }^{2}$, Ole Schmeltz Søgaard ${ }^{1}$ and Søren Jensen-Fangel ${ }^{1}$

\begin{abstract}
Background: Individuals with end-stage renal disease (ESRD) have excess risk of various cancer types. However, the total burden of human papillomavirus-related cancers remains unknown.

Methods: We performed a nationwide observational cohort study during 1994-2010.

For each person with ESRD, we sampled 19 population controls (without ESRD) matched on age, gender and municipality. Participants were followed until first diagnosis of human papillomavirus-related cancer, death, emigration, or 31 December 2010, whichever came first.

Human papillomavirus-related cancers were extracted from Danish medical administrative databases. We considered cancers of the cervix, vulva, vagina, penis, anus, and subsets of head and neck cancers as human papillomavirus-related. We calculated incidence rates of human papillomavirus-related cancer and used Poisson regression to identify risk factors for human papillomavirus-related cancer.

Results: Among 12,293 persons with ESRD and 229,524 population controls we identified 62 and 798 human papillomavirus-related cancers, respectively. Incidence rates of human papillomavirus-related- cancer were 102 per 100,000 person-years (95\% confidence interval [CI]; 79.5-131) among persons with ESRD and 40.8 per 100,000 person-years (95\% Cl; 38.1-43.7) among population controls. ESRD patients had 4.54 (95\% Cl, 2.48-8.31) fold increased risk of anal cancer and 5.81 fold $(95 \% \mathrm{Cl}$; 3.36-10.1) increased risk of vulvovaginal cancer. Adjusted for age, comorbidity, and sex, ESRD patients had 2.41 (95\% Cl; 1.83-3.16) fold increased risk of any human papillomavirusrelated cancer compared with population controls. Compared with dialysis patients renal transplant recipients had an age-adjusted non-significant 1.53 (95\% Cl, 0.91-2.58) fold higher risk of human papillomavirus-related cancer.

Conclusions: Persons with ESRD have excess risk of potentially vaccine-preventable human papillomavirus-related cancers.
\end{abstract}

\footnotetext{
* Correspondence: larsdalg@rm.dk

${ }^{1}$ Department of Infectious Diseases, Aarhus University Hospital, Aarhus, Denmark

Full list of author information is available at the end of the article
} 


\section{Background}

Oncogenic types of human papillomavirus (HPV) can cause cancer of the cervix, vagina, vulva, penis, anus, and a subset of cancers of the head and neck [1-3]. Among persons infected with human immunodefiency virus (HIV), the immunosuppression caused by HIV contributes to the well described excess risk of HPVrelated cancer $[4,5]$. In patients with end-stage renal disease (ESRD) immunosuppressive therapy is used to prevent transplant rejection among transplant recipients and occasionally for treatment of the underlying cause of renal failure among patients on dialysis. Nutritional deficits and uraemia in itself also contributes to the complex dysfunction of both the innate and adaptive immune system that characterizes ESRD patients on dialysis [6-8]. Among transplant recipients, previous studies have shown a markedly increased risk of a wide range of cancers including infection-related cancers [9-13]. Among ESRD patients receiving dialysis, the excess cancer risk appears to be less pronounced and primarily correlated to cancers with a known or suspected viral aetiology $[10,14,15]$. The immune dysfunction in ESRD patients may explain the increased risk of infection-related cancers [10,14].

While most studies have focused on heterogeneous cancer types among patients with ESRD, few studies have assessed the total burden of HPV-related cancers. In light of the recent development in prophylactic HPV vaccination, the interest in HPV-related cancers has been renewed. Vaccines against the two most important oncogenic types of HPV (16 and 18) are now licensed. Among younger healthy individuals HPV vaccination lowers the risk of pre-cancer lesions of the cervix and the risk of anal, vulva, vaginal, and penile infections, with the HPV-types included in the vaccines [16-20]. Further, research in novel vaccines for treatment of existing lesions caused by HPV has shown promising results [21].

A recently published large American cohort study found no increased risk of cervical cancer among solid organ transplant recipients, which contrasts the findings reported by Vajdic and colleagues among Australian kidney transplant recipients $[9,10]$. These findings may be explained by differences in screening procedures prior to transplantation and by differences in study populations. In several studies, HPV-related cancer diagnoses have been grouped with non-HPV-related cancer diagnoses [10-14,22].

The benefit and cost-effectiveness of HPV immunization will depend on the total burden of HPV-related cancer, the proportion of ESRD patients with active HPV infection at the time of vaccination, and the immunogenicity of the vaccines among these patients. Thus, improved knowledge of the epidemiology of HPV-related cancers among ESRD patients are of great importance for the decisions of "if" "who", and "when", to vaccinate.
The main objectives of this Danish nationwide populationbased cohort study were to compare the risk of HPVrelated cancers in the general population with that of patients with ESRD, and to identify risk factors for HPVrelated cancers in patients with ESRD.

\section{Methods}

\section{Study design and setting}

We performed a population-based, observational cohort study among ESRD patients in Denmark during 1 January 1994-31 December 2010. In Denmark, the prevalence of chronic renal failure requiring renal replacement therapy, i.e. dialysis or transplantation is $0.08 \%$ and in 2010 approximately 4,700 persons were living with ESRD [23]. Treatment of ESRD is restricted to 15 hospital departments, 4 of which had status as transplantation centers during the study. In Denmark, the tax-funded health care system provides free of charge treatment for all patients with ESRD. Since 1990, all departments treating ESRD patients report data to the Danish Nephrology Registry (DNR). The DNR contains information on e.g. cause of renal disease, date of first replacement therapy for ESRD, treatment modality, and treatment complications. The DNR has a completeness of $97.2 \%$ [24].

\section{Participants}

We defined ESRD patients as patients treated with renal replacement therapy (dialysis or transplantation) for at least 90 days. Prevalent ESRD patients as of 1 January 1994 or incident thereafter, who were resident in Denmark and at least 14 years of age at the time of their first treatment for ESRD were identified in the DNR and included in the study. For each ESRD patient we sampled 19 population controls matched on age (within 1 year of date of birth), municipality, and gender from the Civil Registration System (CRS) at the day of inclusion in the ESRD registry. Since 1968, the CRS has provided all Danish citizens with a unique 10 digit civil registration number, which allows for accurate linkage between different databases [25].

We obtained information on vital status, sex, date of birth, date of death, and residence of ESRD patients and their population controls from the CRS, which is updated within a week of person's birth, death, or emigration. Population controls were used for comparative analysis. ESRD patients and population controls diagnosed with HPV-related cancer prior to study participation were excluded.

\section{Variables and data sources Definition of HPV-related cancer}

We classified cancers of the anus, vulva, vagina, cervix, penis, and a subset of head and neck cancers as HPVrelated [2]. Cancer diagnoses were coded according to 
the $10^{\text {th }}$ edition of the International Classification of Diseases (ICD-10) as outlined in Table 1. For head and neck cancers, we used the classification published by Ryerson et al. in order to restrict our analyses to the cancer sites most strongly associated with HPV [26].

\section{Identification of patients with HPV-related cancer}

The Danish National Registry of Patients (DNRP) contains information of all hospital admissions in Denmark since 1977 and all outpatient contacts since 1995 $[27,28]$. Variables include civil registration number, dates of admission and discharge, and discharge diagnoses. Since 1994, diagnoses have been coded according to the ICD-10. During 1977-1993 the $8^{\text {th }}$ version (ICD-8) was used. The Danish Cancer Registry (DCR) contains data on incident cancers in Denmark since 1943.The DCR is nationwide and contains ICD-10 diagnoses (as part of the ICD-0 classification) since 1978 [29]. Original diagnoses from 1978-1993 have been electronically recoded from ICD-7 to ICD-10. We classified the earliest date of a HPV-related cancer diagnosis as the date of the first diagnosis of a HPV-related cancer. We used both the DNRP and the DCR to identify HPV-related cancer. In a random sample of 100 persons with a HPV-related cancer, $75 \%$ were identified in the DCR while $25 \%$ was identified in the DNRP alone.

\section{Age, sex, cause of renal failure and comorbidity}

Based on date of birth in the CRS we generated a time varying covariate age (14-49, 50-64, and $\geq 65$ years). Information on cause of renal failure was obtained from the DNR database. Causes of renal failure were categorized as follows: Glomerulonephritis, Diabetes Mellitus types I and II, Chronic Interstitial Nephritis, Hypertension and Chronic renal failure without specification, Polycystic Kidney Disease, Vasculitis, and Other. The Charlson's Comorbidity index (CCI) was used to quantify comorbidity. The CCI is a weighted index based on 19 major disease categories each assigned with a weight $(1,2,3$, or 6$)$. CCI is a validated measure of co-

\begin{tabular}{|c|c|}
\hline $\begin{array}{l}\text { Anatomical } \\
\text { region }\end{array}$ & $\begin{array}{l}\text { ICD-10 diagnoses considered related to human } \\
\text { papillomavirus }\end{array}$ \\
\hline $\begin{array}{l}\text { Head and } \\
\text { neck }^{\mathrm{a}}\end{array}$ & $\begin{array}{l}\text { C01.9, C02.4, C02.8, C09.0, C09.1, C09.8, C09.9, C10.2, } \\
\text { C10.8, C10.9, C14.0, C14.2, C14.8 }\end{array}$ \\
\hline Cervix & C53.0- C53.9 \\
\hline $\begin{array}{l}\text { Vulva and } \\
\text { vagina }\end{array}$ & C51.0- C52.9 \\
\hline Penis & C60.0-C60.9 \\
\hline Anus & C21.0 -C21.8 \\
\hline
\end{tabular}

abased on classification used by Ryerson et al.[26]. morbidity $[30,31]$. We did not include renal diagnoses in the CCI score in this study. Based on discharge diagnoses obtained from the Danish National Registry of Patients (DNRP) we calculated CCI for each ESRD patient and his/her population controls at the time of study entry. We used CCI at the time of first treatment for ESRD to create 3 levels of co-morbidity: low $(\mathrm{CCI}=0)$ medium $(C C I=1-2)$ and high $(C C I \geq 3)$.

\section{Statistical analysis \\ Time at risk}

For each ESRD patient and his/her population controls time at risk started at 1 January 1994 or the date of first treatment for ESRD, whichever came last. Time at risk ended at the date of first diagnosis of a HPV-related cancer, death, emigration, or 31 December 2010, whichever came first.

\section{Incidence rates}

We calculated incidence rates (IRs) and 95\% confidence intervals (95\% CIs) of HPV-related cancers with and without stratification for the five anatomic regions outlined in Table 1. We calculated incidence rates of HPV-related cancer with and without prevalent ESRD patients and only minor differences in risk estimates were found. We therefore chose to include both prevalent and incident ESRD patients in our final analysis. Temporal changes in IRs of first episodes of HPVrelated cancers were analysed in following intervals 1994-97, 1998-01, 2002-2005, and 2006-2010. Incidence rate ratios (IRRs) with corresponding 95\% CIs were calculated for comparison between ESRD patients and population controls. In a separate analysis IRs of HPV-related cancer were compared among two subgroups of ESRD patients: 1) transplant recipients with functioning grafts and 2) dialysis patients. In these analyses, renal replacement therapy i.e. dialysis and transplant recipients with functioning grafts was treated as a time varying covariate. Thus, if the mode of renal replacement therapy was changed during follow-up, a person would contribute to risk time in both subgroups. IR's were compared between the two subgroups with and without stratification for age. For the latter analyses Poisson regression was used: Adjustment for sex, comorbidity and cause of renal failure only caused minor effect on the risk estimates and therefore neither of these variables were included in the final analyses.

\section{Risk factor analysis}

We used Poisson regression to identify potential risk factors for HPV-related cancer among ESRD patients. The following variables were included: Sex, age (14-49, 5064 , and $\geq 65$ years), and the CCI index score. Among the study population 24 patients with ERSD and 227 
population controls were HIV positive. Among HIVpositive persons in our study population, only two (population controls) developed a HPV-related cancer during the study period and we therefore chose not to adjust for HIV status in our analyses. While age and sex are well-known risk factors for cancer, the CCI is not an established risk factor for HPV-related cancer. We therefore calculated adjusted risk estimates with and without the CCI. In the risk factor analysis, we did not stratify for anatomical location of HPV-related cancers.

We used the Stata ${ }^{\circledR}$ statistical software (Statacorp, College Station, Texas) version 11.0 for statistical analysis. The study was approved by the Danish Data Protection Agency.

\section{Results}

\section{Participants}

We excluded 92 ESRD patients (and their matched controls) diagnosed with a HPV-related cancer prior to study participation. A total of 442 population controls diagnosed with HPV-related cancer prior to study participation were also excluded. Persons who died or emigrated before the study period did not contribute to risk time. Consequently 12,293 ESRD patients and 229,524 population controls were included in the study.

\section{Descriptive data}

Table 2 displays basic characteristics of the study population. Males comprised $62.5 \%$ of the ESRD population. The 12,293 ESRD patients and 229,524 population controls provided 60,813 and $1,955,900$ person-years of risk time respectively.

Median time at risk was 3.35 (maximum 17.0) years and 7.85 (maximum 17.0) years among ESRD patients and population controls, respectively. Median age of ESRD patients at the date of their first treatment with renal replacement therapy was 61.6 years.

\section{Outcome data}

During the study period we identified a total of 62 cases of HPV-related cancers among ESRD patients and 798 cases among population controls (Table 3).

\section{Main results}

Table 3 outlines crude IRs of first diagnosis of HPVrelated cancer among ESRD patients and population

Table 2 Baseline characteristics of the study population

\begin{tabular}{|c|c|c|c|}
\hline & End-stage renal disease & Population Controls & $\mathbf{P}$ \\
\hline Number of participants & 12,293 & 229,524 & - \\
\hline Male sex, n (\%) & $7,683(62.5)$ & $143,622(62.6)$ & 0.9 \\
\hline \multicolumn{4}{|l|}{ Age at indexdate ${ }^{a}, \mathrm{n}(\%)$} \\
\hline $14-49$ & $3,516(28.6)$ & $64,464(28.1)$ & \multirow[t]{3}{*}{0.5} \\
\hline $50-64$ & $3,630(29.5)$ & $68,413(29.8)$ & \\
\hline$\geq 65$ & $5,147(41.9)$ & $96,647(42.1)$ & \\
\hline \multicolumn{4}{|l|}{ Comorbidity level at indexdate $^{b}$} \\
\hline Low & 4,231 (34.4) & $169,330(73.8)$ & \multirow[t]{3}{*}{$<0.001$} \\
\hline Medium & $3,663(29.8)$ & $46,539(20.3)$ & \\
\hline High & $4,399(35.8)$ & $13,655(6.0)$ & \\
\hline \multicolumn{4}{|l|}{ Cause of end-stage renal disease } \\
\hline Glomerulonephritis & $1,751(14.2)$ & - & \multirow[t]{3}{*}{ NA } \\
\hline Diabetes I+ II & $2,595(21.1)$ & - & \\
\hline Chronic interstitial nephritis & $1,496(12.2)$ & - & \\
\hline \multicolumn{4}{|l|}{ Hypertension and Chronic renal } \\
\hline failure without specification & $4,019(32.7)$ & - & \\
\hline Adult polycystic kidney disease & $969(7.9)$ & - & \\
\hline Vasculitis & $438(3.6)$ & - & \\
\hline Other & $1,025(8.3)$ & - & \\
\hline \multicolumn{4}{|l|}{ Transplant history } \\
\hline No transplantation & $8,978(73.0)$ & - & \multirow[t]{2}{*}{ NA } \\
\hline$\geq 1$ Transplantation & $3,315(27.0)$ & - & \\
\hline
\end{tabular}

Indexdate: Date of first treatment for end-stage renal disease and date of sampling for controls.

'Three levels of comorbidity was created based on Charlson comorbidity index score (CCI) at the date of first treatment with renal replacement therapy "Low" $(\mathrm{CCl}=0)$, "Medium" $\mathrm{CCl} 1-2$, and "High" $\mathrm{CCl}>2$. Renal diagnosis was not included in the $\mathrm{CCl}$ score in this study. 
Table 3 Crude incidence rates of first episodes of Human papillomavirus-related cancers among persons with endstage renal disease and population controls during 1994-2010

\begin{tabular}{|c|c|c|c|c|c|c|}
\hline Anatomical region & Group & No. & Risk time $^{a}$ & Crude IR ${ }^{\mathrm{b}}(95 \% \mathrm{Cl})$ & IRR $(95 \% \mathrm{Cl})$ & $P$ value \\
\hline \multirow[t]{2}{*}{ Head and neck ${ }^{c}$} & ESRD & 18 & 0.608 & $29.6(18.6-47.0)$ & $1.77(1.10-2.84)$ & 0.02 \\
\hline & Controls & 328 & 19.559 & $16.8(15.1-18.7)$ & & \\
\hline \multirow[t]{2}{*}{ Cervical $^{d}$} & ESRD & 12 & 0.229 & $52.3(29.7-92.1)$ & $1.81(1.01-3.23)$ & 0.05 \\
\hline & Controls & 221 & 7.644 & $28.9(25.3-33.0)$ & & \\
\hline \multirow[t]{2}{*}{ Vulva and vagina $^{d}$} & ESRD & 15 & 0.229 & 65.4 (39.4-108) & $5.81(3.36-10.1)$ & $<0.001$ \\
\hline & Controls & 86 & 7.644 & $11.3(9.11-13.9)$ & & \\
\hline \multirow[t]{2}{*}{ Penis $^{e}$} & ESRD & 5 & 0.379 & $13.2(5.49-31.7)$ & $2.02(0.82-4.98)$ & 0.1 \\
\hline & Controls & 78 & 11.915 & $6.55(5.24-8.17)$ & & \\
\hline \multirow[t]{2}{*}{ Anal } & ESRD & 12 & 0.608 & $19.7(11.2-34.7)$ & $4.54(2.48-8.31)$ & $<0.001$ \\
\hline & Controls & 85 & 19.559 & $4.35(3.51-5.38)$ & & \\
\hline \multirow[t]{2}{*}{ All HPV-related } & ESRD & 62 & 0.608 & $102(79.5-131)$ & $2.50(1.93-3.24)$ & $<0.001$ \\
\hline & Controls & 798 & 19.559 & $40.8(38.1-43.7)$ & & \\
\hline
\end{tabular}

Abbreviations: HPV Human papilloma virus, No. number of HPV-related cancers, CI confidence interval, IR incidence rate, IRR incidence rate ratio, ESRD end-stage renal disease.

a 100,000 years.

b Per 100,000 person-years.

c HPV-related head and neck cancer sites as outlined in Table 1.

d Only females contributed to risk time.

e Only men contributed to risk time.

controls. The overall IRs of first diagnosis of a HPVrelated cancer was 102 (95\% CI, 79.5-131) per 100,000 person-years and 40.8 (95\% CI, 38.1-43.7) per 100,000 person-years among ERSD patients and population controls, respectively. The IR of all HPV-related cancers among ESRD patients was 2.50 (95 CI\%, 1.93-3.24) fold higher than among population controls. The IRs of first episode of HPV-related cancer were significantly higher among ESRD patients compared to the control population in 4 of 5 anatomical regions, most markedly for anal cancer (IRR 4.54; 95\% CI, 2.48-8.31) and vulva/vaginal cancer (IRR 5.81; 95\% CI, 3.36-10.1). The IRRs of cervical cancer and cancers at HPV-related head \& neck sites were 1.81 (95\% CI, 1.01-3.23) and 1.77 (95\% CI, 1.10-2.84) respectively. Figure 1 shows a modest nonsignificant increase in IRs of first diagnosis of HPVrelated cancers among ESRD patients over the study period $(\mathrm{p}=0.57)$, whereas IRs among population controls remained stable.

Among ESRD patients, transplant recipients with functioning grafts had an unadjusted 1.83 (95\% CI, 1.113.01) fold higher risk of HPV-related cancer compared

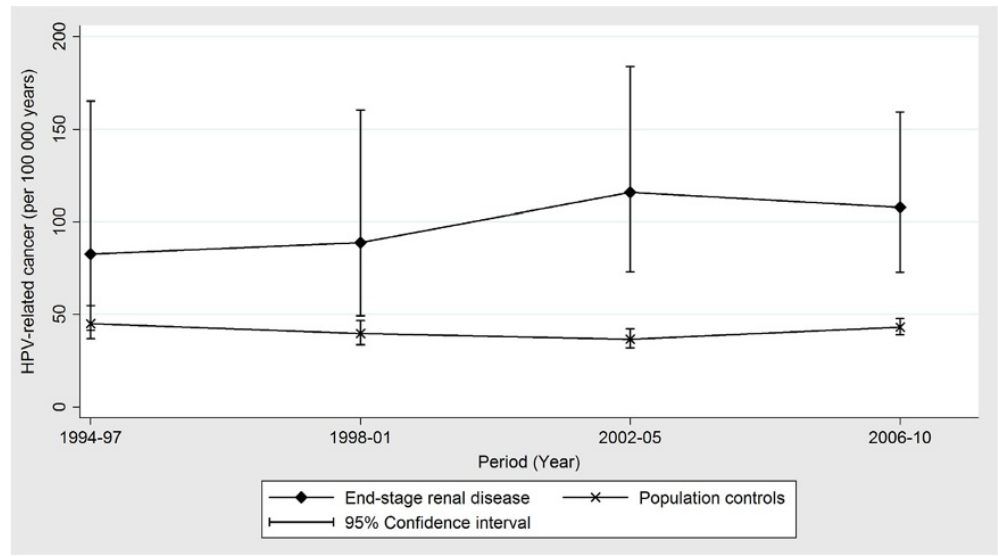

Figure 1 Temporal trends in crude incidence rates of human papillomavirus-related cancers among patients with end-stage renal disease and a matched background population. 
to dialysis patients. When adjusted for age IRR fell to 1.53 (95\% CI, 0.91-2.58) comparing transplant recipients to dialysis patients (Table 4).

\section{Risk factors for HPV-related cancer}

Table 5 illustrates potential risk factors for HPV-related cancers among ESRD patients and population controls. Among ESRD patients female sex (IRR 2.11; 95\% CI, 1.27-3.48) and age 50-64 years (IRR 2.39; 95\% CI, 1.304.39) were risk factors for HPV-related cancer. Among population controls, female sex (IRR 1.54; 95\% CI, 1.34-1.77), age (50-64 years: IRR 2.14; $95 \% \mathrm{CI}, 1.67-$ 2.75 and $\geq 65$ years: IRR $2.75 ; 95 \% \mathrm{CI}, 2.18-3.48)$ and co-morbidity level (medium: IRR 1.41; 95\% CI 1.18-1.69 and high: IRR 2.49 (95\% CI; 1.89-3.28) were all risk factors for HPV related cancer. Interestingly, the IR of HPV-related cancer among ESRD patients was markedly higher at age 50-64 years compared to age 1449 years and age $\geq 65$ years. When adjusted only for age and sex we found an IRR of 2.76 (95\% CI, 2.13-3.58) of HPV-related cancer compared to population controls.

\section{Discussion}

In this nationwide, population-based study, we found that the risk of HPV-related cancer overall was 2.5 fold increased among ERSD patients compared to matched population controls. Interestingly, ESRD patients had a more than fourfold increased risk of anal cancer and female ESRD patients had a nearly six fold increased risk of cancers of vulva and vagina. Major risk factors for HPV-related cancer were age and gender. When adjusted for age, transplant recipients (with a functioning graft) had a modest 1.53 fold increased risk of HPVrelated cancer compared to dialysis patients. Although not significant we cannot rule out an increased risk of HPV-related cancer among transplant recipients due to the low number of cancers in the two groups.

Our study is one of few population-based studies to investigate the burden of HPV-related cancer among unselected individuals with ESRD. The major strengths of our study are the use of population-based nationwide cohorts with high degrees of completeness and minimal loss to follow-up. Because we considered only the first diagnosis of HPV-related cancer our estimates were not biased by multiple episodes of HPV-related cancer occurring in highly susceptible individuals. Further, HPVrelated cancer may increase the risk of development of ESRD and therefore lead to increased risk of HPVrelated cancer among ESRD patients.

Our study had some limitations. The relatively low number of HPV-related cancer limited our opportunities to adjust for potential risk factors and the width of confidence interval complicates the comparison between transplant recipients and patients on dialysis. However, large follow-up time and careful matching yielded estimates of high statistical precision and validity.

We did not have access to information on use of immunosuppressive drugs among ESRD patients and therefore we could not assess the effect of individual drug regimens on the risk of HPV-related cancer. Likewise, we were unable to identify dialysis patients receiving immunosuppressive therapy for their renal disease. Whereas HPV is considered mandatory for development of cervical cancer the etiological fraction of HPV differ among other cancer types considered as HPV-related. If the etiological fractions of HPV are higher among ESRD patients than among population controls this may have led to underestimation of the importance of HPV among ESRD patients in our study. We restricted our analysis to the cancers most strongly associated with HPV in order to minimize the risk of misclassification of nonHPV-cancers as HPV-related. Whereas diagnoses in hospital discharge registries may be revised and therefore not reflect true cancers, cancer registries have a degree of underreporting. We chose to include cancers identified solely in the DNRP in this study. In the DCR, ICD-7 diagnoses were used until 2004. Subsequently diagnoses have been electronically recoded from ICD-7 to ICD-10.

Table 4 Risk of human papillomavirus-related cancer among patients with end-stage renal disease by type of renal replacement therapy

\begin{tabular}{|c|c|c|c|c|c|c|}
\hline & \multicolumn{2}{|c|}{ Dialysis } & \multicolumn{2}{|c|}{ Graft function } & \multirow[b]{2}{*}{ IRR (95\% Cl) } & \multirow[b]{2}{*}{$P$ value } \\
\hline & No. & IR $(95 \% \mathrm{CI})^{\mathrm{a}}$ & No & IR $(95 \% C l)^{a}$ & & \\
\hline Head and neck & 8 & $21.4(10.7-42.7)$ & 10 & $42.9(23.1-79.6)$ & $2.00(0.71-5.85)$ & 0.1 \\
\hline Vulva and vagina & 5 & $35.0(14.5-84.0)$ & 10 & $116(62.3-215)$ & 3.31 (1.13-9.69) & 0.03 \\
\hline Cervix & 8 & $55.9(28.0-112)$ & 4 & $46.3(17.4-123)$ & $0.83(0.25-2.75)$ & 0.8 \\
\hline Anal & 5 & $13.3(5.55-32.1)$ & 7 & $30.0(14.3-62.9)$ & $2.25(0.71-7.08)$ & 0.2 \\
\hline Penis & 3 & $13.0(4.18-40.2)$ & 2 & $13.6(3.40-54.4)$ & $1.05(0.18-6.29)$ & 0.9 \\
\hline All HPV-related & 29 & $77.4(53.8-111)$ & 33 & 141 (100-198) & $1.83(1.08-3.12)$ & 0.02 \\
\hline
\end{tabular}

Abbreviations: No. number cancers, $C l$ confidence interval, $I R$ incidence rate, $I R R$ unadjusted incidence rate ratio, $I R$ incidence rate.

${ }^{a}$ Per 100,000 person-years.

${ }^{b}$ HPV-related head and neck cancer subsites as outlined in Table 1. 
Table 5 Incidence rates of first episodes of human papillomavirus-related cancers by potential risk factors among persons with end stage renal disease and population controls during 1994-2010

\begin{tabular}{|c|c|c|c|c|c|}
\hline Variable & No. & $\mathrm{IR}^{\mathrm{a}}(95 \% \mathrm{Cl})$ & Unadjusted IRR (95\% Cl) & Adjusted IRR ${ }^{\mathrm{b}}(95 \% \mathrm{Cl})^{\mathrm{b}}$ & $P^{c}$ \\
\hline \multicolumn{6}{|l|}{ Total } \\
\hline Controls & 798 & $40.8(38.1-43.7)$ & 1 (reference) & 1 (reference) & - \\
\hline ESRD & 62 & $102(79.5-131)$ & $2.50(1.93-3.24)$ & $2.41(1.83-3.16)$ & $<0.001$ \\
\hline \multicolumn{6}{|l|}{ Sex Controls } \\
\hline Men & 404 & $33.9(30.8-37.4)$ & 1 (reference) & 1 (reference) & - \\
\hline Women & 394 & $51.5(46.7-56.9)$ & $1.52(1.32-1.75)$ & $1.54(1.34-1.77)$ & $<0.001$ \\
\hline \multicolumn{6}{|l|}{ ESRD } \\
\hline Men & 27 & $71.3(48.9-104)$ & 1 & 1 & - \\
\hline Women & 35 & $153(110-213)$ & $2.14(1.30-3.54)$ & $2.11(1.27-3.48)$ & 0.004 \\
\hline \multicolumn{6}{|c|}{ Age (years) Controls } \\
\hline $14-49$ & 83 & $18.8(15.2-23.3)$ & 1 (reference) & 1 (reference) & - \\
\hline $50-64$ & 242 & $40.2(35.5-45.7)$ & $2.14(1.67-2.75)$ & $2.11(1.64-2.71)$ & $<0.001$ \\
\hline$\geq 65$ & 473 & $51.8(47.3-56.7)$ & $2.75(2.18-3.48)$ & $2.51(1.98-3.18)$ & $<0.001$ \\
\hline \multicolumn{6}{|l|}{ ESRD } \\
\hline $14-49$ & 15 & $73.0(44.0-121)$ & 1 (reference) & 1 (reference) & - \\
\hline $50-64$ & 34 & $165(118-231)$ & $2.26(1.23-4.15)$ & $2.39(1.30-4.39)$ & 0.005 \\
\hline$\geq 65$ & 13 & $66.0(38.3-114)$ & $0.90(0.43-1.90)$ & $1.03(0.48-2.19)$ & 0.9 \\
\hline \multicolumn{6}{|c|}{ Comorbidity level ${ }^{d}$ Controls } \\
\hline Low & 591 & $36.8(34.0-39.9)$ & 1 (reference) & 1 (reference) & - \\
\hline Medium & 152 & $52.1(44.4-61.1)$ & $1.41(1.18-1.69)$ & $1.23(1.02-1.47)$ & 0.03 \\
\hline High & 55 & $91.7(70.4-119)$ & $2.49(1.89-3.28)$ & $2.12(1.60-2.81)$ & $<0.001$ \\
\hline \multicolumn{6}{|l|}{ ESRD } \\
\hline Low & 40 & $130(95.1-177)$ & 1 (reference) & 1 (reference) & - \\
\hline Medium & 15 & $98.4(59.3-163)$ & $0.76(0.42-1.37)$ & $0.77(0.42-1.41)$ & 0.4 \\
\hline High & 7 & $47.5(22.6-99.6)$ & $0.37(0.16-0.82)$ & $0.39(0.17-0.87)$ & 0.02 \\
\hline
\end{tabular}

Abbreviations: No number of human papillomavirus-related cancers, $I R$ incidence rate, IRR incidence rate ratio.

a Per 100,000 person-years.

${ }^{\mathrm{b}}$ Adjusted for all variables in the table.

${ }^{c}$ Calculated for the corresponding adjusted incidence rate-ratios.

d 3 levels of comorbidity was created based on Charlson comorbidity index (CCI) score at the date of first treatment with renal replacement therapy "Low" $(\mathrm{CCl}=0)$, "Medium" $\mathrm{CCl} 1-2$, and "High" $\mathrm{CCl}>2$. Renal diagnosis was not included in the $\mathrm{CCl}$ score in this study.

In terms of HPV-related head and neck sites, this may cause some misclassification during the recoding process due to the very specific cancer sites (ICD-10) used to identify these cancers. In these cases DNRP may be more accurate than the DCR. In the remaining cases the validity of cancers identified in the DNPR may be lower than cancers identified in the DCR. Previous studies have indicated high completeness of the DCR and DNP for breast cancer [32], urological cancers [33], colorectal cancers [34], and haematological cancers [35]. To ensure inclusion of all HPV-related cancers we therefore used both the DCR and DNPR.

In a previous study, Birkeland and colleagues reported a 8.6 fold increased risk of cervical cancer among female kidney transplant recipients [13]. In a more recent study, Vajdic and colleagues reported a two and a half fold increased risk of cervical cancer among both transplant recipients and patients on dialysis for ESRD. Shebl et al. reported a 2.12 fold increased risk of cervical cancer among elderly ESRD patients on dialysis [15]. We found a 1.78 fold increased risk of cervical cancer among female ESRD patients and incidence rates of cervical cancer were similar among dialysis patients and patients with functioning grafts. In Denmark, nationwide systematic screening for cervical cancer and pre-cancer lesions of the cervix was implemented during the early 1990's $[36,37]$. Our results therefore reflect the risk of cervical cancer in a setting with systematic cervical screening offered free of charge for the study population. A recent American study by Engels and colleagues reported no increased risk of cervical cancer among solid organ transplant recipients [9]. 
For non-cervical HPV-related cancer among kidney transplant recipients standardized incidence rate-ratios reported by Engels were in concordance with our findings in ESRD patients and the findings by Vajdic and colleagues $[9,10]$.

The cancer risk among dialysis patients is less well studied than among kidney transplant recipients. A previous study suggested that dialysis patients had a modest 1.18 fold increased cancer risk overall, whereas the risk of cervical cancer, penile cancer, and cancer of the oral cavity, was between 1.7 and 4.0 fold increased [14]. However, incomplete data on cancer diagnoses and significant variation in transplantation rates and renal diagnoses may have affected these results [14,38]. In a more recent study, Van Leeuwen et al. reported a rapid decline in risk of non-Hodgkin's lymphoma, melanoma, and cancer of the lip, among kidney transplant recipients following transplant failure and reinstitution of dialysis [39]. Unfortunately, the study had only 7,104 personyears of follow-up during dialysis following transplant failure and only one case of HPV-related cancer was identified among graft-loss patients with consequent uncertainty in risk estimates for HPV-related cancer. Our results suggest that dialysis patients are at increased risk of HPV-related cancer which is in concordance with findings by Vajdic and colleagues [10].

Overall we estimate the external validity of our results to be high due to the population based design, choice of study period, the high quality of the databases used for the study, and the overall concordance with existing literature. Nevertheless differences in renal populations exist and should always be taken into account when applying our results to other renal populations.

Our results suggest that efforts to prevent HPVrelated cancer should focus on dialysis patients as well as transplant recipients. Despite nationwide free of charge screening programs for cervical cancer, ESRD patients are still at increased risk of these cancers. Whether attendance to cervical screening differs among ESRD patients and the control population in our study population is unknown. Given the high IRs of vulvovaginal cancer it is important that the clinicians performing cervical smears are also observant to early signs of these cancers in ESRD patients For non-cervical HPV-related cancers no validated screening programs are currently available. Anal cancer screening have been considered among HIV infected men, but low sensitivity of cytology, high prevalence of anal intraepithelial neoplasia, and uncertainty of the natural history of these lesions complicates development of a screening program. For these cancers, early detection therefore relies on clinician's and patients' awareness on early signs and symptoms of cancer.

Two HPV vaccines are commercially available $[40,41]$. Both vaccines cover the most important oncogenic
HPV-serotypes16 and 18, which are considered responsible for $70 \%$ of cervical cancers and the majority of non-cervical cancers caused by HPV [2]. In healthy individuals $\mathrm{HPV}$-vaccination can prevent reactivation/reinfection with vaccine HPV serotypes to which they were seropositive and DNA negative at study enrolment $[42,43]$. The vaccines have no therapeutic effect against existing HPV-related lesions [17,44,45]. Neither of the vaccines has been formally tested in persons with ESRD but studies among HIV infected men and children have reported high rates of seroconversion. Our study illustrates that the total burden of HPV-related cancers is low among ESRD patients. Further the proportion of cancers caused by HPV infection prevalent at the time of diagnosis of ESRD patients is to our knowledge unknown. If this proportion is high the benefit of HPV vaccination is likely to be limited.

\section{Conclusions}

Our study demonstrates that persons with ESRD have a markedly increased risk of HPV-related cancer compared to matched population controls. Patients with end-stage renal disease had a 4.5 fold increased risk of anal cancer and an almost 6 fold increased risk of vulvovaginal cancer. Transplant recipients only had a modest non-significant 1.53 fold increased risk of HPV-related cancer compared to dialysis patients. Age and female sex were most important risk factors for HPV-related cancer among persons with end-stage renal disease. Future studies of safety, immunogenicity, and efficacy of prophylactic HPV-vaccines among ESRD patients are needed to clarify the benefit of HPV-vaccination in this population.

Competing interests

The authors declare that they have no competing interests.

\section{Authors' contributions}

SJF, BJ, and OSS conceived the study idea. SJF, OSS, LSD, BJ, LJ $\varnothing$ and UF designed the study. OSS and BJ collected the data. LSD, OSS, and UFF analysed the data. All authors interpreted the data. LSD wrote the first draft, and all authors critically reviewed and edited the manuscript and approved the final version.

\section{Acknowledgements}

This work was supported by the Danish Cancer Society. We thank James Heaf and the Danish Society of Nephrology for providing access to DNR data.

\section{Author details}

${ }^{1}$ Department of Infectious Diseases, Aarhus University Hospital, Aarhus, Denmark. ²Department of Nephrology, Aarhus University Hospital, Aarhus, Denmark.

Received: 12 February 2013 Accepted: 1 July 2013

Published: 8 July 2013

\section{References}

1. Kreimer AR, Clifford GM, Boyle P, Franceschi S: Human papillomavirus types in head and neck squamous cell carcinomas worldwide: a systematic review. Cancer Epidemiol Biomarkers Prev 2005, 14(2):467-475. 
2. Parkin DM, Bray F: Chapter 2: The burden of HPV-related cancers. Vaccine 2006, 24 Suppl 3:S3:11-25.

3. De Vuyst H, Clifford GM, Nascimento MC, Madeleine MM, Franceschi S: Prevalence and type distribution of human papillomavirus in carcinoma and intraepithelial neoplasia of the vulva, vagina and anus: a metaanalysis. Int J Cancer 2009, 124(7):1626-1636.

4. van der Burg SH, Palefsky JM: Human Immunodeficiency Virus and Human Papilloma Virus - why HPV-induced lesions do not spontaneously resolve and why therapeutic vaccination can be successful. J Trans/ Med 2009, 7:108.

5. HIV/AIDS NCfIDDo: 1993 revised classification system for HIV infection and expanded surveillance case definition for AIDS among adolescents and adults. MMWR Recommendations and reports : Morbidity and mortality weekly report Recommendations and reports / Centers for Disease Control 1992, 41(RR-17):1-19.

6. Vaziri ND, Pahl MV, Crum A, Norris K: Effect of uremia on structure and function of immune system. J Ren Nutr 2012, 22(1):149-156.

7. Sterling KA, Eftekhari P, Girndt M, Kimmel PL, Raj DS: The immunoregulatory function of vitamin D: implications in chronic kidney disease. Nat Rev Nephrol 2012, 8(7):403-412.

8. Kato S, Chmielewski M, Honda H, Pecoits-Filho R, Matsuo S, Yuzawa Y, Tranaeus A, Stenvinkel P, Lindholm B: Aspects of immune dysfunction in end-stage renal disease. Clin J Am Soc Nephrol 2008, 3(5):1526-1533.

9. Engels EA, Pfeiffer RM, Fraumeni JF Jr, Kasiske BL, Israni AK, Snyder JJ, Wolfe RA, Goodrich NP, Bayakly AR, Clarke CA, et al: Spectrum of cancer risk among US solid organ transplant recipients. JAMA 2011, 306(17):1891-1901.

10. Vajdic CM, McDonald SP, McCredie MRE, van Leeuwen MT, Stewart JH, Law M, Chapman JR, Webster AC, Kaldor JM, Grulich AE: Cancer incidence before and after kidney transplantation. JAMA 2006, 296(23):2823-2831.

11. Villeneuve PJ, Schaubel DE, Fenton SS, Shepherd FA, Jiang Y, Mao Y: Cancer incidence among Canadian kidney transplant recipients. Am J Transplant 2007, 7(4):941-948

12. Adami J, Gabel H, Lindelof B, Ekstrom K, Rydh B, Glimelius B, Ekbom A Adami $\mathrm{HO}$, Granath $\mathrm{F}$ : Cancer risk following organ transplantation: a nationwide cohort study in Sweden. Br J Cancer 2003, 89(7):1221-1227.

13. Birkeland SA, Storm HH, Lamm LU, Barlow L, Blohme I, Forsberg B, Eklund B, Fjeldborg $O$, Friedberg $M$, Frodin $L$, et al: Cancer risk after renal transplantation in the Nordic countries, 1964-1986. Int J Cancer 1995, 60(2):183-189.

14. Maisonneuve P, Agodoa L, Gellert R, Stewart JH, Buccianti G, Lowenfels AB, Wolfe RA, Jones E, Disney AP, Briggs D, et al: Cancer in patients on dialysis for end-stage renal disease: an international collaborative study. Lancet 1999, 354(9173):93-99.

15. Shebl FM, Warren JL, Eggers PW, Engels EA: Cancer risk among elderly persons with end-stage renal disease: a population-based case-control study. BMC Nephrol 2012, 13:65

16. Group FIS: Quadrivalent vaccine against human papillomavirus to prevent high-grade cervical lesions. N Engl J Med 2007, 356(19):1915-1927.

17. Paavonen J, Naud P, Salmeron J, Wheeler CM, Chow SN, Apter D, Kitchener H, Castellsague X, Teixeira JC, Skinner SR, et al: Efficacy of human papillomavirus (HPV)-16/18 AS04-adjuvanted vaccine against cervical infection and precancer caused by oncogenic HPV types (PATRICIA): final analysis of a double-blind, randomised study in young women. Lancet 2009, 374(9686):301-314

18. Garland SM, Hernandez-Avila M, Wheeler CM, Perez G, Harper DM, Leodolter S, Tang GW, Ferris DG, Steben M, Bryan J, et al: Quadrivalent vaccine against human papillomavirus to prevent anogenital diseases. N Engl J Med 2007, 356(19):1928-1943.

19. Kreimer AR, Gonzalez $P$, Katki HA, Porras C, Schiffman M, Rodriguez AC, Solomon D, Jimenez S, Schiller JT, Lowy DR, et al: Efficacy of a bivalent HPV 16/18 vaccine against anal HPV 16/18 infection among young women: a nested analysis within the Costa Rica Vaccine Trial. Lancet Oncol 2011, 12(9):862-870.

20. Palefsky JM, Giuliano AR, Goldstone S, Moreira ED Jr, Aranda C, Jessen H, Hillman R, Ferris D, Coutlee F, Stoler MH, et al: HPV vaccine against anal HPV infection and anal intraepithelial neoplasia. N Engl J Med 2011, 365(17):1576-1585

21. Kenter GG, Welters MJ, Valentijn AR, Lowik MJ, der Meer DM B-v, Vloon AP, Essahsah F, Fathers LM, Offringa R, Drijfhout JW, et al: Vaccination against
HPV-16 oncoproteins for vulvar intraepithelial neoplasia. N Engl J Med 2009, 361(19):1838-1847.

22. Birkeland SA, Lokkegaard $\mathrm{H}$, Storm HH: Cancer risk in patients on dialysis and after renal transplantation. Lancet 2000, 355(9218):1886-1887.

23. Danish Nephrology Registry Annual report 2010. [http://www.nephrology.dk/ Publikationer/Landsregister/\%C3\%85rsrapport\%202010.pdf]

24. Hommel K, Rasmussen S, Madsen M, Kamper AL: The Danish registry on regular dialysis and transplantation: completeness and validity of incident patient registration. Nephrol Dial Transplant 2010, 25(3):947-951.

25. Pedersen CB, Gotzsche H, Moller JO, Mortensen PB: The Danish Civil Registration System. A cohort of eight million persons. Dan Med Bull 2006, 53(4):441-449.

26. Ryerson AB, Peters ES, Coughlin SS, Chen WW, Gillison ML, Reichman ME, Wu X, Chaturvedi AK, Kawaoka K: Burden of potentially human papillomavirus-associated cancers of the oropharynx and oral cavity in the US, 1998-2003. Cancer 2008, 113(10 Suppl):2901-2909.

27. Lynge $E$, Sandegaard $J L$, Rebolj M: The Danish national patient register. Scand J Public Health 2011, 39(7 Suppl):30-33.

28. Andersen TF, Madsen M, Jorgensen J, Mellemkjoer L, Olsen JH: The Danish national hospital register. A valuable source of data for modern health sciences. Dan Med Bull 1999, 46(3):263-268.

29. Gjerstorff ML: The Danish cancer registry. Scand J Public Health 2011, 39(7 Suppl):42-45

30. Charlson ME, Pompei P, Ales KL, MacKenzie CR: A new method of classifying prognostic comorbidity in longitudinal studies: development and validation. J Chronic Dis 1987, 40(5):373-383.

31. Thygesen SK, Christiansen CF, Christensen S, Lash TL, Sorensen HT: The predictive value of ICD-10 diagnostic coding used to assess Charlson comorbidity index conditions in the population-based Danish National Registry of Patients. BMC Med Res Methodol 2011, 11:83.

32. Jensen AR, Overgaard J, Storm HH: Validity of breast cancer in the Danish Cancer Registry. A study based on clinical records from one county in Denmark. Eur J Cancer Prev 2002, 11(4):359-364.

33. Gammelager $H$, Christiansen CF, Johansen MB, Borre M, Schoonen M, Sorensen HT: Quality of urological cancer diagnoses in the Danish National Registry of Patients. Eur J Cancer Prev 2012, 21(6):545-551.

34. Helqvist L, Erichsen R, Gammelager $H$, Johansen MB, Sorensen HT: Quality of ICD-10 colorectal cancer diagnosis codes in the Danish National Registry of Patients. Eur J Cancer Care (Engl) 2012, 21(6):722-727.

35. Norgaard M, Skriver MV, Gregersen H, Pedersen G, Schonheyder HC Sorensen HT: The data quality of haematological malignancy ICD-10 diagnoses in a population-based hospital discharge registry. Eur J Cancer Prev 2005, 14(3):201-206

36. Bigaard J, Hariri J, Lynge E: Cervical cancer screening in Denmark. Eur J Cancer 2000, 36(17):2198-2204.

37. Lynge E, Arffmann E, Erbs K, Hansen KC, Henriksen B, Holten IW, Holund B, Jakobsen $A B$, Jespersen $N B$, Olesen $F$, et al: [Status of preventive screening for uterine cervix cancer in Denmark in 1994]. Ugeskr Laeger 1994, 156 (4):471-473.

38. Rayner HC, Pisoni RL, Bommer J, Canaud B, Hecking E, Locatelli F, Piera L, Bragg-Gresham JL, Feldman HI, Goodkin DA, et al: Mortality and hospitalization in haemodialysis patients in five European countries: results from the Dialysis Outcomes and Practice Patterns Study (DOPPS). Nephrol Dial Transplant 2004, 19(1):108-120.

39. van Leeuwen MT, Webster AC, McCredie MR, Stewart JH, McDonald SP, Amin J, Kaldor JM, Chapman JR, Vajdic CM, Grulich AE: Effect of reduced immunosuppression after kidney transplant failure on risk of cancer: population based retrospective cohort study. BMJ 2010, 340:c570.

40. D'Andrilli G, Bovicelli A, Giordano A: HPV vaccines: state of the art. J Cell Physiol 2010, 224(3):601-604.

41. Hellner K, Munger K: Human papillomaviruses as therapeutic targets in human cancer. J Clin Oncol 2011, 29(13):1785-1794.

42. Future II study Group: Prophylactic efficacy of a quadrivalent human papillomavirus (HPV) vaccine in women with virological evidence of HPV infection. J Infect Dis 2007, 196(10):1438-1446.

43. Olsson SE, Kjaer SK, Sigurdsson K, Iversen OE, Hernandez-Avila M, Wheeler CM, Perez G, Brown DR, Koutsky LA, Tay EH, et al: Evaluation of quadrivalent HPV $6 / 11 / 16 / 18$ vaccine efficacy against cervical and anogenital disease in subjects with serological evidence of prior vaccine type HPV infection. Hum Vaccin 2009, 5(10):696-704. 
44. Keam SJ, Harper DM: Human papillomavirus types 16 and 18 vaccine (recombinant, AS04 adjuvanted, adsorbed) [Cervarix]. Drugs 2008, 68(3):359-372.

45. McCormack PL, Joura EA: Quadrivalent human papillomavirus (types 6, $11,16,18)$ recombinant vaccine $($ Gardasil( $(\mathrm{R}))$ : a review of its use in the prevention of premalignant genital lesions, genital cancer and genital warts in women. Drugs 2010, 70(18):2449-2474.

doi:10.1186/1471-2369-14-137

Cite this article as: Skov Dalgaard et al.: Risk of human papillomavirusrelated cancers among kidney transplant recipients and patients receiving chronic dialysis - an observational cohort study. BMC Nephrology 2013 14:137.

\section{Submit your next manuscript to BioMed Central and take full advantage of:}

- Convenient online submission

- Thorough peer review

- No space constraints or color figure charges

- Immediate publication on acceptance

- Inclusion in PubMed, CAS, Scopus and Google Scholar

- Research which is freely available for redistribution 